Editorial

\title{
Environmental Flows Determination and Monitoring with Hydraulic Habitat Models-Pushing the Boundaries of Habitat Models Application
}

\author{
Piotr Parasiewicz ${ }^{1, *,+}{ }^{\dagger}$ Paweł Prus ${ }^{1}$, Christos Theodoropoulos ${ }^{2,3}{ }^{\oplus}$, Knut Alfredsen ${ }^{4}(\mathbb{D}$, \\ Mikołaj Adamczyk 1,5 (D), Claudio Comoglio ${ }^{6}(\mathbb{D})$ and Paolo Vezza ${ }^{6}(\mathbb{D}$ \\ 1 Inland Fisheries Institute, Oczapowskiego 10, 10-719 Olsztyn, Poland; p.prus@infish.com.pl (P.P.); \\ mikolaj_adamczyk@op.pl (M.A.) \\ 2 Hellenic Centre for Marine Research, Institute of Marine Biological Resources and Inland Waters, $46.7 \mathrm{~km}$ \\ Athens-Sounio Ave., 19013 Anavyssos, Greece; ctheodor@hcmr.gr \\ 3 Department of Water Resources and Environmental Engineering, School of Civil Engineering, National \\ Technical University of Athens, Iroon Polytechniou 5 Str., 15780 Athens, Greece \\ 4 Department of Civil and Environmental Engineering, Norwegian University of Science and Technology, \\ 7031 Trondheim, Norway; knut.alfredsen@ntnu.no \\ 5 Platform of Hydraulic Constructions (PL-LCH), École Polytechnique Fédérale de Lausanne (EPFL), \\ CH-1015 Lausanne, Switzerland \\ 6 Department of Environment, Land and Infrastructure Engineering (DIATI), Politecnico di Torino, Corso \\ Duca degli Abruzzi 24, 10129 Torino, Italy; claudio.comoglio@polito.it (C.C.); paolo.vezza@polito.it (P.V.) \\ * Correspondence: p.parasiewicz@infish.com.pl \\ + Current address: Inland Fisheries Institute, Department of River Fisheries, Żabieniec, Główna 48, \\ 05-500 Piaseczno, Poland.
}

Received: 8 August 2019; Accepted: 10 September 2019; Published: 19 September 2019

\begin{abstract}
Hydraulic habitat simulation models were designed for the quantitative determination of environmental flows that consider the needs of aquatic fauna in rivers and streams. In the past 50 years, the modeling techniques were significantly developed, but expectations associated with model utility also increased. Nowadays, the tools are expected to be applicable across a range of spatial and temporal scales and to protect entire aquatic communities, while being inexpensive as well as easy to use in administrative and legal environments. Addressing these challenges is the focus of this volume. We invited papers that present recent developments in habitat modeling, supported by real life case studies. The submitted papers well represent the wide applicability of habitat simulation models, allowing us to address both ends of river management requirements: the ability to address very detailed site specific issues as well as the ability to address the coarse scale applications necessary in regional management.
\end{abstract}

Keywords: habitat simulation models; upscaling; water management; fish; macroinvertebrates

\section{Introduction}

At their inception, hydraulic habitat models aimed at utilizing engineering tools for predicting detailed hydraulic changes associated with flow reduction and at assessing its impact on biotas selection of suitable habitats. By their technical nature, the models operated at a very fine scale that demanded extensive data collection from small areas. The classic application of hydraulic habitat models focuses on the determination of environmental flows using the habitat suitability of select species of interest at a given location. For many decades it was and still is a "bread and butter" of environmental consulting in area of conflict resolution. 
The intensity of the required resources limited the model applications to site-specific studies. Yet, the ability of quantitative assessment and simulation of biological response to physical changes of the environment is of great interest to river resources management, which seeks the answer to the questions of biological consequences of planned actions. It should be also an immanent step in Environmental Impact Assessments (EIA), according to Article 4.1 of Water Framework Directive (WFD) [1] - the non-deterioration principle. Such actions are not only site specific, but are frequently applied at watershed or regional scales. Hence, the demand for the application of habitat modeling tools at these coarser scales is increasing. However, the requirement of resources-intensive data collection has to be removed first. This needs the development of new techniques, which will allow for the generalization of the models to coarser scales (upscaling) without sacrificing model performance.

At the same time, the site specific detail cannot be lost as it is necessary to address a variety of boundary conditions, which may have strong influence on the biological response. Issues such as water quality, hydromorphological alteration, or hydro-peaking can be well addressed with hydraulic habitat models and incorporated as a boundary conditions of environmental flow settings. Nevertheless, the appropriate techniques and approaches need to be further developed and improved.

The papers presented in this volume push the boundaries of application beyond the standard use by addressing these both ends of the spectrum of the scientific innovation in hydraulic habitat models for the monitoring and assessment of environmental flows.

\section{Overview of This Special Issue}

\subsection{Site Specificity}

Implementation of environmental flows is sometimes constrained by local conditions and types of water uses. There are a number of site specific characteristics of environmental variables that may have a strong influence on the determination of environmental flows. These aspects can be roughly divided into those caused by human induced alterations of river hydraulic and riverbed morphology, and those related to geographic location with its specific geohydrological characteristics. There are also operational constraints that frequently need to be taken into account. The first three papers demonstrate these influences in specific case studies and present how these aspects can be incorporated in sustainable hydropower management practices.

The paper by Choi et al. [2] investigates the impact of baseflow contribution i.e., seepage of water from the underground into streams, on the volume of environmental flows. In the presented study, the hypothesis that this influence is profound has been tested. It was documented that the baseflow effects significantly increase the habitat suitability in the study reach. To restore the aquatic habitat, a scenario for modifying dam operations through natural flow patterns is presented using the Building Block Approach (BBA). The results indicate that modifying the dam operations through restoration to natural flow regimes but also through inclusion of the baseflow are advantageous to fish habitats.

The study by Zingraff-Hamed et al. [3] presents a model-based method to estimate the most sustainable scenario of water resources sharing between nature and human needs. Four management scenarios have been considered: (A) maximum use of the resources for humans; (B) slight increase in the minimum water flow; (C) medium increase in the minimum water flow; and, (D) without diversion for hydroelectric production. Under the current hydromorphological conditions, model outputs indicated that different life stages of investigated fish species showed preferences for different scenarios, and that none of the four scenarios provided permanently suitable habitat conditions for the fish community. The study concluded that due to significant hydromorphological alteration of the site, the discharge management should be combined with restoration actions that would favor all species at the same time. The modeling procedure that is presented may help to identify the discharge scenario that is most efficient for maintaining target fish species under realistic water use conditions.

Covering peak demand in the energy market and balancing loads in a system with increasing intermittent energy production through non-storable renewables are situations determining that 
hydropower with reservoir storage plays an important role. The hydropeaking operation can lead to rapidly fluctuating water levels in rivers downstream of the hydropower outlet, and this has implications for physical and ecological processes [4]. This includes flushing and short-time flooding, as well as periodic dewatering of riverine habitats. Understanding the effect of variable flow on the physical conditions is necessary to evaluate impacts and propose mitigation measures. The advent of remotely sensed river bathymetry data through green LiDAR provides the foundation for detailed studies of hydropeaking in rivers. The paper of Juarez et al. [5] uses a two dimensional hydraulic model to analyze impacts of peaking operation on a two-kilometer long river reach downstream of the Hol1 power plant in Norway. A high-resolution laser-derived river bathymetry is used to evaluate draw down speeds, dried out areas and dampening effects along the river reach and how potential stranding sites are distributed in the reach. Further, a method to mitigate the effects through turbine operation is evaluated and costs of changes in operation is estimated. The paper shows how the integration of high-resolution data, detailed modeling and hydropower operation can be used to better understand impacts and evaluate the effects of mitigation measures.

\subsection{Upscaling}

Upscaling is a crucial element for extending the applicability of habitat models beyond site specific studies. As defined by Parasiewicz [6] there are three major categories of upscaling: biological (generalization from species to communities), spatial (from site to watershed), and temporal (from snapshots to long term time series analysis). One important element of biological upscaling is also the generalization of habitat suitability criteria. Such criteria are the deciding element of physical habitat models and developing them with high level of specificity is very resources consuming as it requires collection of high resolution data. On the other hand, there is a large body of literature containing the information about species behavior that could be utilized for this purpose.

The paper by Adamczyk et al. [7] tests the use of more generic habitat use criteria for habitat model development. The authors refer to the concept of inductive and deductive models. The inductive statistical models are based on field data obtained from multiple sampling and the deductive approach uses expert knowledge and literature to create conditional habitat suitability criteria (CHSC). The paper investigates the accuracy of both approaches and its influence on the modeling results. Observations of bullhead distribution in various habitats in the Alpine river were used to validate MesoHABSIM model predictions created with both indices. The inductive model was shown to be more precise and reflect site- and species-specific characteristics. In particular, the statistical model predicts less suitable habitats than the expert-literature one. According to precautionary principle, it is therefore recommended to be used for protection of vulnerable species. Although more generic, the deductive model validated very well too, indicating its utility in broader scale studies.

A similar concept is investigated by Theodoropoulos et al. [8] focused on developing generic models for benthic macroinvertebrates. Using a reference dataset of 380 microhabitats, collected from nine unpolluted, geographically widespread sites over three seasons, multiple algorithms for calculating habitat suitability were tested. It was observed that, in multiple locations with similar hydromorphological and hydraulic properties, seasonal and geographically confined macroinvertebrate samples can be pooled to facilitate model-based environmental flow assessments. This would happen without a significant loss of the model's predictive accuracy. In $65-90 \%$ of the cases studied, the generic-model predictions lay within the acceptable range of environmental flow predictions made by local and seasonally specific habitat models.

The paper by Parasiewicz et al. [9] takes the ultimate upscaling step towards application of habitat model-based environmental flows at a regional scale. It includes all three categories of upscaling. Spatial upscaling was performed by dividing the riverine freshwater bodies of Poland into macrohabitat types, each of which supported specific expected fish community. To address biological upscaling not only were expected fish communities established for specific river types, but species were also grouped into functional guilds with similar habitat requirements. To address temporal upscaling habitat use, 
guilds were established for particular bio-periods, such as: foraging, spawning (spring and autumn - for Salmonids) or overwintering. The specific habitat preferences of each guild (water depth and velocity, bottom substrate type, cover availability) were then derived from literature data to establish CHSC criteria. Finally, long term habitat time series are developed, and continuous under threshold duration analysis is used to establish seasonal environmental flow thresholds, which are specific for each macrohabitat type and bioperiod.

The final paper by Vassoney et al. [10] demonstrates how the indices derived from the application of mesoscale habitat models allow for the assessment of spatio-temporal alterations of habitat structure, due to changes in the river hydromorphological conditions (not only due to water withdrawals, but also to hydro-technical and regulation works, climate-change, etc.). Furthermore, the paper demonstrates how these indices can be adequately integrated into a multi-criteria analysis (MCA) framework supporting decision-making processes by the competent authorities. This approach can be adopted for the assessment of a single site or at a catchment scale, analyzing several withdrawals located on the same watercourse and/or functionally connected to each other.

\section{Conclusions}

This Special Issue presented the versatility and utility of habitat models for environmental flow determination. It cannot cover all the possibilities for model applications in this context, but highlights the possibility of addressing a wide range of issues from the micro to macro scale. It also nicely presents the development direction, which scientists undertook in order to expand the utility of the models, as well as to better use their capabilities. These capabilities allow for the detection of site specific aspects that impact environmental flows, as well as for the possibility of applying these tools in the watershed and regional scale context. Specifically, the papers have shown that:

- Base flows play a crucial role in establishing environmental flows;

- Hydromorphological alteration is an important limiting factor that needs to be taken into account as a co-variate of environmental flows;

- New emerging remote sensing technologies can dramatically improve the model precision, allowing us to address site specific conditions, such as those related to hydropeaking;

- The inductive statistical models were shown to be more precise, reflecting site- and species-specific characteristics, while the deductive model is advised in broader scale and predevelopment studies;

- The biological habitat use criteria can be generalized for more geographically widespread, cost-effective model-based environmental flow assessments.

- $\quad$ Apart from fish, habitat suitability models based on macroinvertebrate-community metrics can be applied in large scale contexts.

- $\quad$ The habitat models can be upscaled to establish regional rules for environmental flows.

- $\quad$ The models and produced indices can be incorporated into the Multi Criteria Decision Support framework for watersheds and regions.

The special issue clearly demonstrates that the use of habitat models for the determination and monitoring of the environment is no longer limited to site specific studies. Furthermore, the level of detail obtainable with this method is no longer limited by the intensity of resources used to collect environmental data. It is not only a management tool but also a discovery tool, which allows us to better identify the processes and mechanisms governing the riverine ecosystems.

Conflicts of Interest: The authors declare no conflict of interest.

\section{References}

1. European Union. Directive of the European Parliament and the Council 2000/60/EC establishing a framework for community action in the field of water policy. Off. J. Eur. Commun. 2000, L 327/1, 1-73. 
2. Choi, B.; Kang, H.; Lee, W.H. Baseflow Contribution to Streamflow and Aquatic Habitats Using Physical Habitat Simulations. Water 2018, 10, 1304. [CrossRef]

3. Zingraff-Hamed, A.; Noack, M.; Greulich, S.; Schwarzwälder, K.; Pauleit, S.; Wantzen, K.M. Model-Based Evaluation of the Effects of River Discharge Modulations on Physical Fish Habitat Quality. Water 2018, 10, 374. [CrossRef]

4. Harby, A.M. Rapid flow fluctuations and Impacts on Fish and the Aquatic Ecosystem. In Ecohydraulics-An Integrated Approach; Maddock, I.P., Harby, A., Kemp, P.S., Wood, P.J., Eds.; Wiley: Chichester, UK, 2013.

5. Juárez, A.; Adeva-Bustos, A.; Alfredsen, K.; Dønnum, B.O. Performance of A Two-Dimensional Hydraulic Model for the Evaluation of Stranding Areas and Characterization of Rapid Fluctuations in Hydropeaking Rivers. Water 2019, 11, 201. [CrossRef]

6. Parasiewicz, P. Upscaling: Integrating habitat model into river management. Can. Water Resour. J. 2003, 28, 283-300. [CrossRef]

7. Adamczyk, M.; Parasiewicz, P.; Vezza, P.; Prus, P.; De Cesare, G. Empirical Validation of MesoHABSIM Models Developed with Different Habitat Suitability Criteria for Bullhead Cottus Gobio L. As an Indicator Species. Water 2019, 11, 726. [CrossRef]

8. Theodoropoulos, C.; Skoulikidis, N.; Stamou, A.; Dimitriou, E. Spatiotemporal Variation in Benthic-Invertebrates-Based Physical Habitat Modeling: Can We Use Generic Instead of Local and Season-Specific Habitat Suitability Criteria? Water 2018, 10, 1508. [CrossRef]

9. Parasiewicz, P.; Prus, P.; Suska, K.; Marcinkowski, P. “E = mc2” of Environmental Flows: A Conceptual Framework for Establishing a Fish-Biological Foundation for a Regionally Applicable Environmental Low-Flow Formula. Water 2018, 10, 1501. [CrossRef]

10. Vassoney, E.; Mammoliti Mochet, A.; Rocco, R.; Maddalena, R.; Vezza, P.; Comoglio, C. Integrating Meso-Scale Habitat Modeling in the Multicriteria Analysis (MCA) Process for the Assessment of Hydropower Sustainability. Water 2019, 11, 640. [CrossRef]

(C) 2019 by the authors. Licensee MDPI, Basel, Switzerland. This article is an open access article distributed under the terms and conditions of the Creative Commons Attribution (CC BY) license (http://creativecommons.org/licenses/by/4.0/). 